\title{
Het broeden van de Geoorde Fuut (Podiceps nigricollis Brehm) op de Ankeveensehe plassen in Mei 1918
}

\author{
DOOR \\ P. L. STEENHUIZEN, \\ Praeparateur aan het Kon. Zoologisch Genootschap „Natura Artis Magistra”.
}

(Met één Tekstfiguur).

In mijn vijfentwintigjarige loopbaan als praeparateur aan het Genootschap „Natura Artis Magistra". waren mij een paar malen exemplaren van de Geoorde Fuut (Podiceps nigricollis Brehm) in handen gekomen, waarvan zelfs één met broedvlek. Dit fraai gevederde, eigenaardige duikertje met zijn zilverwitte borst, zwarte kop, hals en rug, roestroode flanken, zijn rudimentaire staartpennen en oogjes met vermiljoenroode iris, vooral kenbaar aan de verlengde goudgeelachtige vederen bij de oorstreek, waaraan het zijn naam ontleent, en wiens broedgebied zich vrijwel over geheel Europa uitstrekt, zou dus waarschijnlijk, zij het dan ook bij hooge uitzondering, als broedvogel onze veenplassen bewonen.

Enkele malen werd het broeden dezer soort in Nederland vermeld, echter zonder dat hiervan voldoende bewijs geleverd werd, zoodat hieraan geen wetenschappelijke waarde gehecht kan worden.

Op mijn vroegere photographische tochten, welke zich over verscheidene jaren $\ddot{u}$ itstrekten en waarin ik voornamelijk de Provinciën Noord- en Zuid-Holland met hare eilanden bezocht, is het mij nooit mogen gelukken ook maar een spoor van het voorkomen van deze Futensoort als broedvogel te ontdekken.

Ook onze bekende vogelphotograaf, de Heer Bürdet, wiens photographische excursies zich over geheel Nederland uitstrekten, is ondanks ijverige nasporingen dit geluk niet. deelachtig mogen worden, zoodat het photographeeren van dezen interessanten gevederden moerasbewoner bij zijn. nest ons beider vrome wensch gebleven is.

Hoezeer werd ik verrast, toen mijn zoon op één zijner tochten naar de plassen van Ankeveen op 5 Mei 1918 toevalligerwijze met zijn roeiboot terecht kwam in een kolonie van een twaalftal op 't water drijivende nesten, gedeeltelijk bezet met eieren, gedeeltelijk in aanbouw, en in welker bouw hij dadelijk het karakter der Futennesten herkende, zonder echter de soort te kunnen vaststellen, hoewel de geringere grootte der nesten en het feit, dat hier vele op een beperkte oppervlakte bij elkaar gebouwd waren, uitsloot, dat men hier met nesten van de gewone Fuut (Podiceps cristatus Linn.) te doen zou hebben, hoewel deze laatste soort op de Ankeveensche plassen veelvuldig voorkomt.

Deze nesten toch waren, voor zoover ze met eieren bezet waren, evenals bij de gewone Fuut bij 't naderen van de boot, door de vogels zorgvuldig met eenig plantenmateriaal overdekt, zoodat een leek in die drijvende hoopjes halfvergane planten wel geen vogelnesten, en dian nog wel met eieren bezet, herkend zou hebben. Ook was hier evenals bij nesten der 
andere Futensoorten, de bodem op het zelfde niveau als 't wateroppervlak, zoodat de eieren op een vrij vochtigen ondergrond rustten.

Ze waren gelijk die der Futen in het algemeen van half vergane plantenresten zooals bladeren van het riet (Phragmites), en bladeren der lischdodde (Typha) gebouwd, maar wat vooral opviel, was de aanwezigheid van vele stengels der waterpest (Elodea canadensis Casp.).

- De vogels zelve gedroegen zich evenals alle andere Futen en doken bij naderend gevaar snel van het nest weg, na eerst de eieren overdekt te hebben, en lieten eenigen tijd daarna, meenende dat het gevaar verdwenen was, een helder sterk vibreerend fluitend geluid als loktoon hooren. De kleine kolonie strekte zich slechts over een oppervlak van ongeveer honderd vierkante Meter uit, enkele nesten waren niet meer dan één Meter van elkaar verwijderd, zoodat hier terecht van̈ een' kolonie gesproken kan worden.

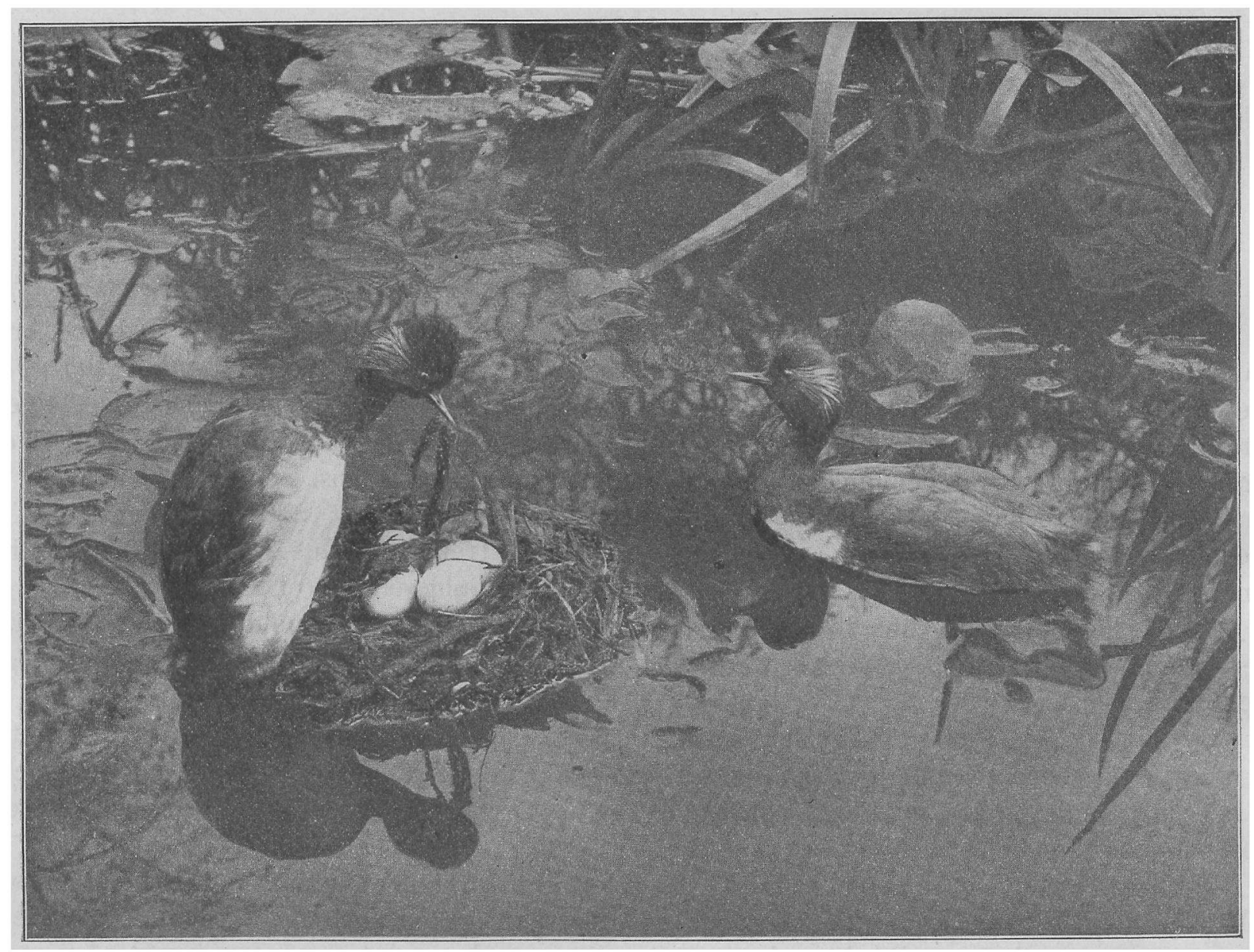

Mannetje en wijfje van de Geoorde Funt (Podiceps nigricollis Brehm.) bij het drijvend nest, het wijfje ontbloot de eieren Opgezet en gephotografeerd door den schrijver.

Een enkele dezer nesten was met vier eieren bezet, terwịl op andere slechts drie, twee en één ei aanwezig waren. Daar nu een volledig legsel uit minstens vier eieren bestaat, blijkt duidelijk dat de kolonie op dat tijdstip nog in wording was.

Een legsel van vier eieren werd voor het Museum van het Genootschap mede genomen. Deze eieren, 45 m.M. lang en 30 m.M. breed, waarvan de schaal uit een dikke poreuze kalklaag bestaat, dus in structuur nauwkeurig overeenkomende met de schaal der eieren van de gewone Fuut, zijn vuilwit van kleur.

Daar het reeds vrijwel bekend was, dat de Geoorde Fuut in kolonie broedt, lag bet voor de hand, dat men hier met deze soort te doen had. Om mij echter zekerheid te verschaffen, verzocht ik mijn zoon, een manlijk en vrouwelijk exemplaar bij 't nest te schieten 
en tevens dat nest mede te brengen, hetgeen op 12 Mei 1918 plaats vond. Die beide exemplaren en het nest, welke door mij voor het Museum „Fauna Neerlandica” van Artis gepraepareerd zijn, bleken nu werkelijk de lang gezochte te zijn.

Op mijn talrijke bezoeken gedurende vele jaren aan de plassen van Ankeveen had ik daar nooit de Geoorde Fuut aangetroffen, en ook de jachtopziener, welke vele jaren reeds op de plassen jaagt en vischt, had deze vogelsoort nimmer gezien, waardoor aangenomen kan worden, dat de Geoorde Fuit in Mei 1918 zich als broedvogel is gaan vestigen op de Ankeveensche plassen.

Ongelukkigerwijze was het tijdstip roor de vestiging niet bijzonder gunstig, de voedselnood toch was oorzaak dat dit jaar overal eieren geraapt werden, waarvan de Ankeveensche plassen zeker niet verschoond bleven. Zooals dan ook later bleek, is er van de kolonie helaas weinig terecht gekomen. Toch schijnt het enkele paren gelukt te zijn, jongen voort te brengen; de jachtopziener toch heeft later een paar malen oude vogels met jongen van zeer nabij gezien, duikende voor zijn roeiboot uit.

Willen wij hopen, dat het volgende jaar de Geoorde Fuut weer tot de broedvogels der Ankeveensche plassen mag behooren, wellicht zullen zij zich naar het nabij gelegen Naardermeer verspreiden. Moge het de Vereeniging tot behoud van Natuurmonumenten gegeven worden, dezen interessanten moerasbewoner onder hare hoede te nemen. 